Original Scientific Article

\title{
SOW PRODUCTIVITY ON COMMERCIAL PIG FARMS IN THE REPUBLIC OF MACEDONIA
}

\author{
Branko Angjelovski ${ }^{1}$, Aleksandar Cvetkovikj ${ }^{1}$, Slavcho Mrenoshki ${ }^{1}$, \\ Ivica Gjurovski ${ }^{1}$, Toni Dejanoski ${ }^{2}$, Toni Dovenski ${ }^{1}$ \\ ${ }^{1}$ Faculty of Veterinary Medicine, Ss. Cyril and Methodius University in Skopje \\ R. Macedonia \\ ${ }^{2}$ Pig farm, ZZ Edinstvo, v. Chelopek, R. Macedonia
}

Received 10 January 2014; Received in revised form 2 May 2014; Accepted 11 June 2014

\begin{abstract}
The objectives of the present study were to determine the production performances of sows on commercial pig farms in the Republic of Macedonia, to compare the differences in sow productivity data between small and large farms and to examine interrelationships of key production parameters among farms with different sizes. The study was retrospectively based and included the annual (2012) analyses of the sow productivity data in small $(<200$ sows, $n=4)$ and large $(200-1000$ sows, $n=5)$ commercial pig farms. The data was statistically evaluated and compared with the known literature. Sows productivity was greater on the small farms compared to the large ones. The small farms had larger litter per sow (PBL), more pigs born alive (PBA), higher weaning weight (WW) and more pigs weaned per sow per litter (PWSL) than the large ones $(\mathrm{p}<0.001)$. Small farms also had greater farrowing rate $(F R)(p<0.01)$. Higher replacement rate $(R R)$, lower average parity $(A P)$, greater number of litters per sow per year (LSY) and higher sow death rate (SDR) were observed in large farms $(p<0.001)$. The large farms also had less non-productive days (NPD) than the small farms $(\mathrm{p}<0.001)$. Different intensity of correlations also were observed for several productive parameters among the farm groups. The data obtained in this study show that sow productivity on Macedonian pig farms is lower than in EU countries. Small herds are more efficient than the large herds. Despite all limitations, our study provides information for veterinarians regarding reproductive parameters of sows and their interrelationships on Macedonian pig farms. Further investigation should be made in order to identify whether specific management factors have effect on the productivity of the breeding herd.
\end{abstract}

Key words: sow productivity, pig farms, Republic of Macedonia

\section{INTRODUCTION}

Pig production efficiency is mainly controlled by the performance of the reproductive herd (1). Reproduction in pigs is a very complex process and involves many factors such as diet, genetics, housing, social surroundings, temperature, diseases and management (2). Sow productivity is primary measured by the number of piglets born alive, pigs

\footnotetext{
Corresponding author: Prof. Toni Dovenski, $\mathrm{PhD}$

E-mail address: dovenski@fvm.ukim.edu.mk

Present address: Faculty of Veterinary Medicine-Skopje;

Department of Reproduction; Lazar Pop Trajkov 5-7, Skopje,

Macedonia;

Phone: ++38923240767

Copyright: (C) 2014 Angjelovski B. This is an open-access article published under the terms of the Creative Commons Attribution License which permits unrestricted use, distribution, and reproduction in any medium, provided the original author and source are credited. Competing Interests: The authors have declared that no competing interests exist.

Available Online First: 21 June 2014

http://dx.doi.org/10.14432/j.macvetrev.2014.06.016
}

weaned per sow per litter, pigs weaned per sow per year, litters per sow per year, piglet survival until weaning, weaning weight and non-productive days $(3,4,5)$. The low level of reproductive performance may not only reduce the sow productivity, but also is one of the reasons that may cause considerable financial loss due to increased neonatal mortality, decreased piglet growth and expenses for treatment $(2,6,7)$. The target of reproductive performance is to have a minimum of 2.2 litters per sow per year with an average of 10 pigs per litter at weaning which is at least a total of 22 weaned pigs for each sow in the herd (2). Additionally, other parameters including sow death rate, replacement rate, conception and farrowing rate have been shown to have some potential to impact sow production performances on a herd level $(2,4,6,8)$. Recording of sow productivity data is essential and cost-effective for efficient sow health management (9). In case of low herd productivity, sow production targets and 
standards are useful instruments for veterinarians and swine producers to diagnose reproductive failure and to improve breeding herd productivity (4).

Comparisons of sow productivity data with corresponding values on the farms of similar capacity are effective tools for detecting problem areas (10). Analysis of sow productivity data and variation between production parameters have been documented among breeding herds with different sizes $(6,7,11)$ and performances $(4,5,12,13)$.

There is no similar data about sow productivity on commercial pig farms in the Republic of Macedonia, so the objectives of the present study were to give an overview of sow reproductive performances, to compare the production differences between small and large farms and to examine interrelationships of production parameters among farms with various herd sizes.

\section{MATERIALS AND METHODS}

The survey included nine commercial pig farms with a total production of 80000 finisher pigs per year which is $40 \%$ of the total pork produced in the Republic of Macedonia on an annual basis (14).
The selection of the farms was based according to the number of sows kept in the herd (minimum 80 sows) and willingness of the farmers to participate in the survey. Herd size was determined by using the average number of sows in farm production units followed by classification into small $(<200$ sows, $n=4)$ and large (200-1000 sows, $n=5)$ farms. Genetic selection of the breeding females was performed only in two large farms. In one of the large farm gilts were Landrace-Yorkshire F1 cross produced from the mating of purebred Landrace sires to purebred Yorkshire females and reciprocal cross. The other farm produced F1 gilts (Topigs 40) based on the A-line (Large white type) and B-line (Landrace type). The other large farms used to breed Topigs 40, while small farms used to breed two genetic lines (Landrace-Yorkshire F1 and Topigs 40) purchased from both farms that were performed genetic selection. All farms were farrow to finishing units (the common way of breeding in Macedonia). The location of the farms is shown with dotted squares on Figure 1. The study was retrospectively based and included the annual (2012) analyses of the sow production data collected from the farm record sheets.

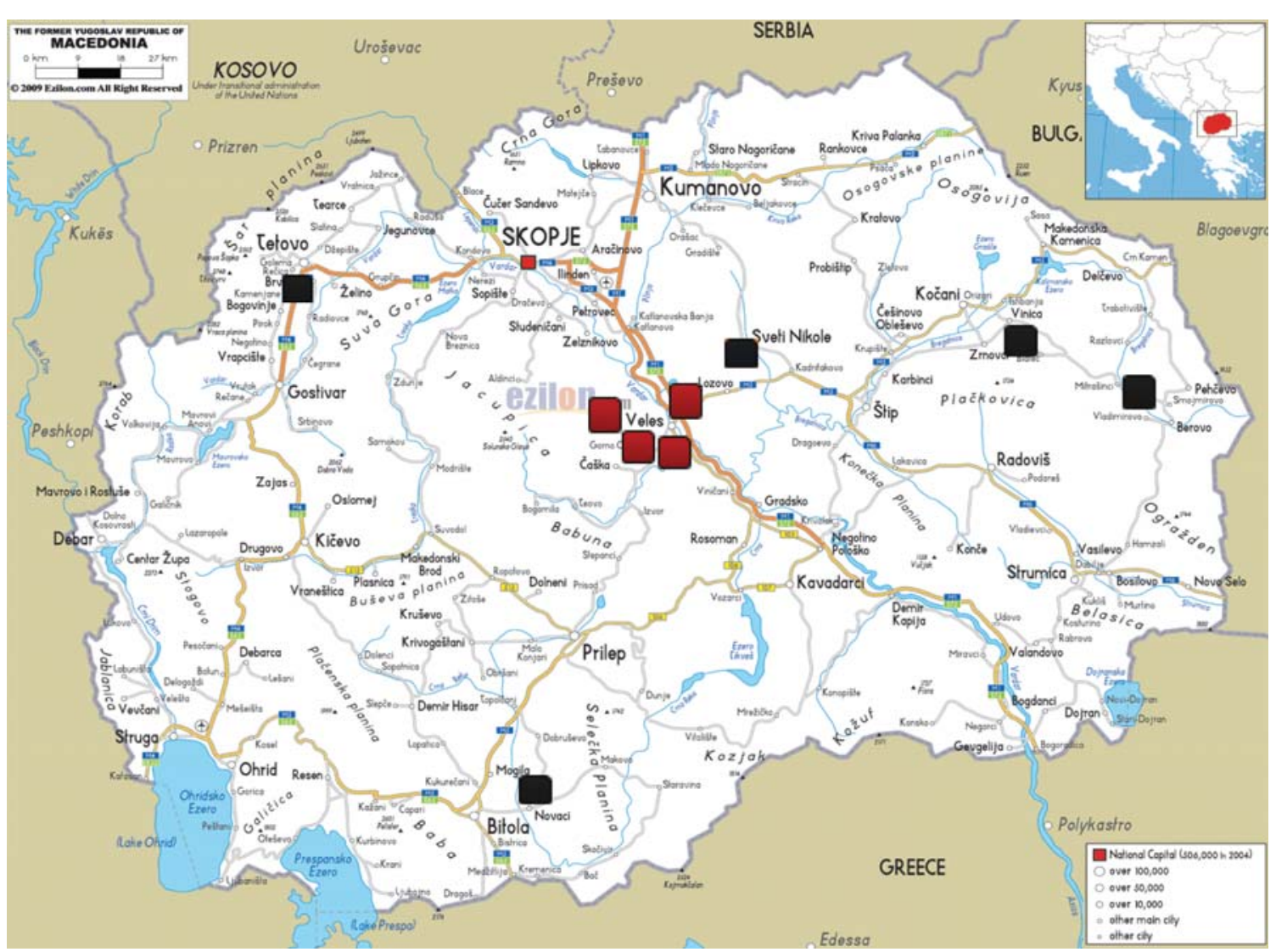

Figure 1. Map of Republic of Macedonia showing the locations of the selected pig farms (dark squares indicate large farms, red squares indicate small farms). Source: http://www.ezilon.com/maps/europe/macedonia-maps.htm 
Table 1. Production parameters of sows on the surveyed pig farms

\begin{tabular}{lcccl}
\hline & Large farms & Small farms & All farms & \\
\hline Mean \pm SD & Mean \pm SD & Mean \pm SD & P- value \\
\hline NS & $718 \pm 208.77$ & $125 \pm 48.80$ & $454.4 \pm 350.04$ & $\mathrm{p}<0.001$ \\
\hline CR \% & $84.22 \pm 5.09$ & $83.33 \pm 6.67$ & $83.71 \pm 4.16$ & $\mathrm{p}>0.05$ \\
\hline FR \% & $78.51 \pm 3.90$ & $79.64 \pm 7.67$ & $79.11 \pm 5.17$ & $\mathrm{p}<0.01$ \\
\hline AP & $3.79 \pm 0.81$ & $5.43 \pm 0.93$ & $4.48 \pm 0.94$ & $\mathrm{p}<0.001$ \\
\hline RR \% & $45.84 \pm 7.75$ & $20.00 \pm 5.01$ & $34.36 \pm 14.43$ & $\mathrm{p}<0.001$ \\
\hline PBL & $11.74 \pm 0.79$ & $13.76 \pm 1.30$ & $12.64 \pm 1.38$ & $\mathrm{p}<0.001$ \\
\hline PBA & $10.88 \pm 0.39$ & $11.98 \pm 1.24$ & $11.38 \pm 1.03$ & $\mathrm{p}<0.001$ \\
\hline PWSL & $9.78 \pm 0.64$ & $10.83 \pm 1.00$ & $10.25 \pm 0.97$ & $\mathrm{p}<0.001$ \\
\hline LSY & $2.22 \pm 0.09$ & $2.14 \pm 0.11$ & $2.19 \pm 0.09$ & $\mathrm{p}<0.001$ \\
\hline PWSY & $21.93 \pm 1.35$ & $23.24 \pm 1.92$ & $22.50 \pm 1.83$ & $\mathrm{p}>0.05$ \\
\hline PWM \% & $10.05 \pm 1.59$ & $10.75 \pm 0.87$ & $10.37 \pm 1.41$ & $\mathrm{p}>0.05$ \\
\hline AWW kg & $7.20 \pm 0.95$ & $8.12 \pm 1.16$ & $7.72 \pm 1.12$ & $\mathrm{p}<0.001$ \\
\hline SDR \% & $5.79 \pm 2.88$ & $1.33 \pm 0.37$ & $3.81 \pm 3.24$ & $\mathrm{p}<0.001$ \\
\hline NPD & $46.00 \pm 7.96$ & $55.22 \pm 8.08$ & $50.16 \pm 9.71$ & $\mathrm{p}<0.001$ \\
\hline & & & & \\
\hline
\end{tabular}

The production data: number of sows (NS); replacement rate (RR); average parity (AP); conception rate (CR); farrowing rate (FR); number of litters per sow per year (LSY); total piglets born per litter (PBL); piglets born alive per litter (PBA); pigs weaned per sow per litter (PWSL); pigs weaned per sow per year (PWSY); average weaning weight (AWW); sow death rate (SDR); preweaning mortality (PWM) and non-productive days (NPD) were chosen, recorded and processed (on a monthly basis and then summarized for a whole year) as recommended by Glen et al. (2).

Statistical analyses were performed using Daniel's XL Toolbox ver. 6.50 (http://xltoolbox. sourceforge.net) and all results were expressed as mean $\pm \mathrm{SD}$ (standard deviation). To determine whether there are inter-farm groups statistical differences, the data were subjected to one-way analysis of variance (ANOVA). Correlation analysis between the key production parameters [PBA, PWSL, PWSY, NPD, LSY, AWW, PWM (3, 4, 5)] was performed in the both farm groups. The results were considered statistically different at 0.01 significance level $(\mathrm{p}<0.01)$.

\section{RESULTS}

Themean \pm SDvalues of the production parameters for the surveyed farms are shown in Table 1. The small farms had greater number of PBL, PBA and PWSL, higher AWW, lower RR and higher AP, but longer NPD than the large farms. Additionally, small farms had greater FR $(p<0.01)$ and lower LSY and SDR than the large ones $(\mathrm{p}<0.001)$. Although, we found higher PWSY in small farms $(23.24 \pm 1.92$ vs. $21.93 \pm 1.35)$, significant differences were not observed ( $p>0.05$ ).

The data of the correlation analysis between the key production parameters in both farm groups are shown in Table 2. A negative correlation was found between LSY and PBA for the small farms, whereas no correlation was found between LSY and PBA for the large farms. Longer NPD on small farms was positively correlated with PBA and PWSL, while all six measurements (PBA, AWW, PWSL, PWSY, LSY and PWM) were negatively correlated with NPD on the others farms. Greater PBA on small farms was positively correlated with PWSY, whereas no correlation was found between PBA and 
Table 2. Correlation coefficients between reproductive parameters of sows on large and small farms

\begin{tabular}{|c|c|c|c|c|c|c|c|}
\hline $\begin{array}{l}\text { Large } \\
\text { farms }\end{array}$ & & & & & & & \\
\hline & PBA & AWW & PWSL & PWSY & LSY & PWM & NPD \\
\hline \multicolumn{8}{|l|}{ PBA } \\
\hline AWW & $0.39^{*}$ & & & & & & \\
\hline PWSL & $0.42^{* *}$ & $0.34^{*}$ & & & & & \\
\hline PWSY & 0.19 & $0.45^{* *}$ & -0.06 & & & & \\
\hline LSY & 0.10 & 0.04 & 0.07 & $0.51^{* *}$ & & & \\
\hline PWM & 0.22 & $0.45^{* *}$ & -0.08 & $0.95^{* *}$ & $0.53^{* *}$ & & \\
\hline NPD & $-0.35^{*}$ & $-0.39^{*}$ & $-0.56^{* *}$ & $-0.65^{* *}$ & $-0.46^{* *}$ & $-0.57^{*}$ & \\
\hline \multicolumn{8}{|l|}{$\begin{array}{l}\text { Small } \\
\text { farms }\end{array}$} \\
\hline & PBA & AWW & PWSL & PWSY & LSY & PWM & NPD \\
\hline \multicolumn{8}{|l|}{ PBA } \\
\hline AWW & $0.55^{* *}$ & & & & & & \\
\hline PWSL & $0.89^{* *}$ & $0.63^{* *}$ & & & & & \\
\hline PWSY & $0.79^{* *}$ & $0.87^{* *}$ & $0.83^{* *}$ & & & & \\
\hline LSY & $-0.40^{*}$ & 0.24 & -0.34 & 0.04 & & & \\
\hline PWM & 0.31 & $0.91^{* *}$ & 0.37 & $0.70^{* *}$ & 0.36 & & \\
\hline NPD & $0.53^{* *}$ & -0.26 & $0.44^{*}$ & 0.00 & $-0.75^{* *}$ & $-0.45^{*}$ & \\
\hline
\end{tabular}

* significant at level $\mathrm{p}<0.01 ;{ }^{* *}$ significant at level $\mathrm{p}<0.001$

PWSY for the large farms. Furthermore, LSY was positively correlated with PWSY and with PWM only on the large farms.

\section{DISCUSSION}

The sow production efficiency can be assessed and compared in many different ways (15). There are numerous references that encompasses sow productivity data, but recent studies $(4,5,6,8$, $11,12,13)$ are mainly focused on herd to herd variation. The comparative analysis of the sow productivity data in all surveyed farms was based on the data reported by the British Pig Executive (BPEX) which is a division of the Agriculture and Horticulture Development Board [(AHDB)] (16). The BPEX is in charge of collection and processing the data connected with pig production in EU member states and globally. More precisely, this division currently includes 15 countries referred to as selected countries EU-15. The mean number of PBA that we found on Macedonian farms (table 1) is 1.32 lower than the average of 12.7 pigs in EU-15 for 2012. There are two major factors that may have a reducing effect on the number of PBA. First is a lower PBA as a result of weak prevention measures such as lack of vaccination against certain infectious diseases (Porcine respiratory and reproductive diseases, Parvovirosis, Morbus Aujeszky) and the second is due to bad sow management (poor genetic selection, old age, feeding strategy, etc) during the gestation and farrowing period. The number of PWSL found in our survey was only 0.85 pigs less than the average of PWSL in EU -15. On the other hand, the number of PWSY in Macedonia is almost three pigs fewer than the average of 25.4 obtained in European countries. The lower number of PWSY in our surveyed farms is strongly associated with lower LSY compared to higher LSY (2.3) reported by BPEX. It seems very likely that the main reason for the differences in the number of weaned pigs is the low farrowing index in Macedonian farms resulting from poor management system for e.g. low replacement rates of the breeding herd $(34.36 \%)$ as compared with $46 \%$ in EU-15. The replacement rate is influenced by many factors such as herd size, genetic turnover, breeds, definition of the average inventory and population dynamics (17). In general, purebred populations suggest that genetic selection has been effective for improving reproductive performance (18). Higher replacement rates are to be expected in the herds to ensure genetic improvement and to reduce genetic lag for 
commercial producers (17). The low replacement rate in our survey indirectly shows that culling of sows does not take place due to their poor efficiency, but due to their health condition such as lameness, chronic mastitis, small numbers of piglets in the first litter, age, etc. These data show that Macedonian swine breeders pay too minor attention to the replacement rate regarding genetic selection which leads to lower genetics improvement in the breeding herd. Furthermore, the surveyed pig farms had quite lower PWM and SDR compared with 12.7\% PWM and 5.7\% SDR found in EU-15. The lower PWM in our survey could be associated with the smaller litter size, since as litter size increases, birth weight decreases and the number of small pigs per litter increases (18). The smaller pigs unlike the heavier pigs are more prone to hypothermia which is one of the major causes of mortality in neonatal piglets (6). In addition, larger breeding herd is one of the potential reason for higher SDR, because as breeding herd size increases the risk of sow death rate increases too (19). The sow mortality risk increases by $0.44 \%$ as herd size increases by 500 females (7).

The small farms had greater sow productivity regarding PBL, PBA, PWSL, AWW, FR and SDR compared with the large farms (table 1). These results are in contradiction with the results recently published by Dors et al. (11). Greater average parity in the small farms suggests that there is a practice to breed elder sows in order to improve herd efficiency. This management practice was found in highperforming farms in Japan (4), but was not found in high-performing U.S. farms $(5,12)$. Interestingly, shorter NPD and greater LSY do not improve the number of PWSY in larger farms. The higher RR found in large herds and its negative implication on sow productivity is similar to previously published results for high-performing farms in USA (5), but different from the results found in high-performing Japanese farms (4). The problem associated with high RR and lower sow productivity could be associated with infertility in the summer and autumn seasons (6). The higher sow efficiency found in small farms is likely due to the fact that the owners of these farms are focused mainly on pig production implementing new advanced technologies in the production process. The negative correlation between NPD and PBA and negative correlation between NPD and PWSL or PWSY determined in the large farms, is maybe one of the major causes for reduced sow productivity. Unlike the large farms, in the small ones we found positive correlation between NPD and PBA or PWSL which is consistent with previous reports in high-performing farms $(4,13)$. Also positive correlation observed between PBA and PWSY or PWSL show higher sow productivity in the small farms. The negative correlation found between LSY and PBA indicate better sow fertility in these farms. This result is also in accordance with previous finding in high-performing farms (4).

The data obtained in this survey show that sows production efficiency on Macedonian pig farms is lower than in EU countries. Small herds are more efficient than large herds, but even these are less efficient than EU swine herds. Our study is certainly incomplete, because farms were not randomly selected, the number of farms was small and some data (multiple mating, litters per farrowing crate per year, lactation duration, culling rates) were missing. However, even with these limitations, our research gives the veterinarians useful information concerning sows production parameters and interrelationships on Macedonian pig farms. Further investigation should be made on the influence of various management factors that may have constraints to efficient breeding herd productivity.

\section{REFERENCES}

1. Ate, I.U., Oyedipe, E.O. (2011). Sow reproductive performance in institutional herds in Benue State Nigeria. J. Reprod. \& Infertility 2 (2): 24-31.

2. Almond, G.W., William L. F., Batista, L., D’Allaire, S. (2006). Diseases of the reproductive system. In Straw, B.E., Zimmerman J. J., D’Allaire, S., Taylor, D.J. (Eds), Diseases of swine $9^{\text {th }}$ ed. (pp.113-148). Oxford: Blackwell Publishing.

3. Van der Leek, M.L., Becker, H.N. (1993). Reproductive management problems in swine. Current Therapy 3. In Howard, J. L. (ed), Food Animal Practice. (pp: 805-809). Philadelphia: W. B. Saunders Co.

4. Koketsu, J. (2002). Reproductive productivity measurements in japanese swine breeding herds. J. Vet. Med. Sci. 64 (3): 195-198. http://dx.doi.org/10.1292/jvms.64.195 PMid:11999436

5. King, V.L., Koketsu,Y., Reeves,D., Xue, J., Dial, G.D. (1998). Management factors associated with swine breeding-herd productivity in the United States. Prev. Vet. Med. 35: 255-264. http://dx.doi.org/10.1016/S0167-5877(98)00068-3 
6. Knox, R.V., Rodriguez-Zas, S.L., Sloter, N.L., McNamara, K.A., Gall, T.J., Levis, D.G., Safranski, T. J., Singleton, W. L. (2013). An analysis of survey data by size of the breeding herd for the reproductive management practices of North American sow farms. J. Anim. Sci. 91: 433-445.

http://dx.doi.org/10.2527/jas.2012-5189

PMid:23097401

7. Cutler, R. S., Fahy, V. A., Cronin, G. M., Murray, S.E. (2006). Preweaning mortality. In: Straw, B.E., Zimmerman J. J., D’Allaire, S., Taylor, D.J (Eds). Diseases of swine $9^{\text {th }}$ ed. (pp. 993-1110). Oxford: Blackwell Publishing.

8. Koketsu, Y. (2000). Retrospective analysis of trends and production factors associated with sow mortality on swine-breeding farms in USA. Prev. Vet. Med. 56: 249-256.

http://dx.doi.org/10.1016/S0167-5877(00)00153-7

9. Wilson, M. R., Friendship, R. M., McMillan, I., Hacker, R. R., Piper, R., Swaminathan, S. (1986). A survey of productivity and its component interrelationships in Canadian swine herds. J. Anim. Sci. 62: 576-582.

10. Koketsu, Y., Takahashi, H., Akachi, K. (1999). Longevity, lifetime pig production and productivity, and age at first conception in a cohort of gilts observed over six years on commercial farms. J. Vet. Med. Sci. 61: 1001-1005.

http://dx.doi.org/10.1292/jvms.61.1001

PMid:10535505

11. Dors, A., Czyżewska, E., Pomorska-Mól1, M., Kołacz, R. Pejsak, Z. (2013). Effect of various husbandry conditions on the production parameters of swine herds in Poland. Pol. J. Vet. Sci. 16 (4): 707-713.

http://dx.doi.org/10.2478/pjvs-2013-0100

PMid:24597306

12. Stein, T. E., Duffy, S. J., Wickstrom, S. (1990). Differences in production values between high- and low-productivity swine breeding herds. J. Anim. Sci. 68: 3972-3979.

PMid:2286540
13. Koketsu, Y. (2000). Productivity characteristic of high-performing commercial swine breeding farms. J. Am. Vet. Med. Assoc. 216: 376-379.

http://dx.doi.org/10.2460/javma.2000.216.376 PMid:10668537

14. Petrovska, M. (2011). Efficiency of pig farm production in the Republic of Macedonia. Master's thesis. Swedish University of Agricultural Sciences Uppsala.

15. Deen J, Dee S., Morrison, R. B., Radostis, O. M. (2001). Health and production management in swine herds. Radostis, O. M. (Ed). In Herd health food animal production medicine $3^{\text {rd }}$ ed. Philadelphia: W.B. Saunders Company.

16. BPEX (2012). Pig cost of production in selected countries. Agriculture and horticulture development board. Stoneleigh Park, Kenilworth.

17. D'Allaire, S., Drolet, R. (2006). Longevity in breeding animals. In: Straw, B.E., Zimmerman J. J., D'Allaire, S., Taylor, D.J (Eds). Diseases of swine $9^{\text {th }}$ ed. (pp. 993-1110). Oxford: Blackwell Publishing.

18. Moeller, S. J., Goodwin, R. N., Johnson, R. K., Mabry, J. W., Baas, T. J., Robison, O. W. (2004). The national pork producers council maternal line national genetic evaluation program: A comparison of six maternal genetic lines for female productivity measures over four parities. J. Anim. Sci. 82: 41-53. PMid:14753347

19. Christensen, G., Vraa-Andersen, L., Mousing, J. (1995). Causes of mortality among sows in Danish pig herds. Vet. Rec. 137: 395-399. http://dx.doi.org/10.1136/vr.137.16.395 PMid:8545936 